\title{
SURGICAL MANAGEMENT OF SPASTIC DIPARESIS IN SELECTED CASES OF CEREBRAL PALSY BY "SELECTIVE DORSAL RHIZOTOMY" OPERATION
}

\author{
By \\ Ahmed Nasser Abdul-Hamid Al-Sayed, Ma'moun Abo-Shousha, \\ Mohammed Ahmed El-Labbad, Alaa Rashad Ibrahim \\ Department of Neurosurgery, Faculty of Medicine, Al-Azhar University \\ Corresponding author: Ahmed Nasser Abdul-Hamid Al-Sayed, \\ E-mail: ahmedalsayed8085@gmail.com
}

\begin{abstract}
Background: Spasticity affects a large number of children, mainly in the setting of cerebral palsy, however, only a few paediatric neurosurgeons deal with this problem. This is mainly due to the fact that until 1979, when Fasano has published the first series of selective dorsal rhizotomy (SDR), neurosurgeons were able to provide such children only a modest help.

Objectives: This work aims to study the effect of performing selective dorsal rhizotomy operation on patients suffering from spastic diparesis due to cerebral palsy, and the aim of surgery is to relieve the present spasticity, which is predominantly seen in the lower limbs, and to improve motor function.

Patients and methods: This study was done on 30 patients with ages (4-12) years old, with mean age 8 years old, included patients from both sexes (16 males, 14 females), on Al-Azhar University Hospital and Dar Elshefa Hospital, in the period from January 2019 to August 2020.

Results: In our study, we achieved significant results in our patients with sectioning 30-60\% of rootlets, with preservation of motor power and no sensory loss. According to our results, an important factor that may improve outcome and prognosis of patients is the pre-operative mental state, as patients with acceptable mental ability has the potential to participate in more active physiotherapy programs that improve outcome greatly. However, even with decreased mentality there is post-operative decrease in muscle tone and reflexes, which may aid in making patient's decubitus less prone to pressure sores, and make the patient easier to handle, so, the proper care can be achieved. Also according to our study, the higher the grade of Aschworth's score is a good prognostic factor of achieving faster improvement of spasticity and gait.

Conclusion: selective dorsal rhizotomy is not a cure for cerebral palsy. The procedure offers spastic CP children improved motor capabilities and increased levels of functioning. Achieving maximal benefits depends on how much and which of the posterior rootlets are cut.
\end{abstract}

Keywords: Surgical Management Spastic Diparesis, Cerebral Palsy, Selective Dorsal Rhizotomy Operation

\section{INTRODUCTION}

Cerebral palsy has been defined as a non-progressive condition affecting those parts of the brain, which control movements, and postures. It is clear, therefore, that the term Cerebral Palsy doesn't refer to a single disease and entity, but rather represents a combination of motor disorders, sensory defects and mental impairment, varying from mild to severe, caused by injury to the central 
nervous system in the peri natal period (Lieber el al., 2017).

Cerebral palsy $(\mathrm{CP})$ has an incidence and prevalence rate of about two per 1000 in children (Nahm et al., 2018).

Spasticity is a major clinical feature of over $75 \%$ of cases of $\mathrm{CP}$ and is conventionally considered to be a major cause of discomfort, gait abnormalities, and functional limitations for persons with CP. Many resources have been directed at the treatment of spasticity and the current treatment choices include oral medications, orthotics, orthopaedic surgical procedures, electrical stimulation, intramuscular injections, physiotherapy, 'selective' dorsal rhizotomy and continuous intrathecal baclofen infusion. 'Selective' dorsal rhizotomy (SDR) emerged as a popular surgical intervention for spasticity in North America and elsewhere since the early 1980s. History of the development of this procedure, including the introduction of electrophysiological criteria for 'selecting' dorsal root tissue for transection, has been reviewed repeatedly in the literature (Graham et al., 2018).

Many published results of open consecutive surgical series strongly suggested that SDR reduced spasticity substantially, improved function, and involved no unacceptable short-term risks when carried out by experienced interdisciplinary clinical teams (Lynn et al., 2010).

This work aims to study the effect of performing selective dorsal rhizotomy operation on patients suffering from spastic diparesis due to cerebral palsy, and the aim of surgery is to relieve the present spasticity, which is predominantly seen in the lower limbs, and to improve motor function.

\section{PATIENTS AND METHODS}

This study was done on 30 patients with ages (4-12) years old, with mean age 8 years old, included patients from both sexes (16 males, 14 females), on Al-Azhar university hospital and Dar El-shefa hospital, in the period from January 2019 to August 2020.

All patients were assessed preoperatively emphasizing on the history of factors that may predispose to cerebral palsy or may hinder the functional outcome postoperatively, as following:

- Personal history(Age and sex), Past history (Peri natal period complications including pre natal maternal diseases as anemia, hemorrhages or infections, natal complications as birth traumas, asphyxiation of infant, post natal infections, jaundice, or hydrocephalus manifestations, and history of sphincteric control.

- Family history emphasizing on consanguinity, and presence of siblings with same condition.

- Neurological examination mainly, motor power, tone, modified Ashworth's Score, reflexes, gait abnormalities, and mental status.

- General examination including inspection for congenital anomalies, and orthopedic examination to detect deformities, joints mobility and stiffness.

- Investigations were done in form of CT or MRI brain, MRI and CT spine to assess the presence of scoliosis or 
other spinal deformities or cord anomalies, and X-ray of pelvis and any deformed bones and joints.

\section{Inclusion criteria:}

A. Children Younger than 18 Years:

1. At least 2 years of age.

2. Diagnosis of spastic diparesis.

3. Some form of independent mobility (e.g., crawling or walking) with or without an assistive device.

4. Patients exhibit potential for improvement in functional skills after dorsal rhizotomy.

\section{B. Adults between Ages 19 and 40} Years:

1. Diagnosis of spastic diparesis.

2. History of diagnosed cerebral palsy.

3. Currently ambulates independently with or without assistive device.

4. Patients exhibit potential for functional gains after dorsal rhizotomy.

5. Patients exhibit motivation to perform home exercise program.

\section{Exclusion criteria:}

1. Association with chorea and/or athetosis.

2. History of post natal meningitis and/or hydrocephalus, except if the patient is showing acceptable mental state that may aid in the post-operative physiotherapy participation to improve outcome of functional improvement to the most.

Laboratory investigations: Preoperative laboratory assessment (CBC, PC, PT,
INR, urea, creatinine, ALT, AST), and blood preparation were done.

Surgical consent: Was acquired from parents with explanation of potential benefits and complications.

\section{Surgical management by SDR:}

- Anaethesia: Intubation is performed while the patient is under deep sevoflurane anesthesia; sometimes intubation is facilitated by shortlasting muscle relaxants (e.g., atracurium or vecuronium) Anesthesia is induced with sevoflurane, and is maintained with fentanyl and sevoflurane. Propofol is avoided because it alters EMG activities. The patient receives a dose of antibiotic before a skin incision. A bladder catheter is inserted.

- Position and EMG electrodes insertion: The patient is positioned prone with EMG needle electrodes placed into five muscle groups of each leg (bilaterally in the adductor longus, vastus lateralis, anterior tibialis, medial hamstring, and medial gastrocnemius muscles) and the external anal sphincter muscle. Longacting neuromuscular blocking agents are avoided because intact neuromuscular activity is required for intraoperative EMG.

\section{Postoperative Care:}

Patients stay overnight in the intensive care unit where they receive an intravenous proper analgesia with wide coverage of antibiotics. Patients are transferred to the ward the next day, then, patients are allowed to sit, and physical therapy is started. The patients are discharged to home after stabilization and 
receive outpatient physical therapy from local therapists.

Postoperative Course: With spastic diplegia the operation reduces spasticity in 26 patients from our selected group (86\%), no change in 3 patients $(10 \%)$, while there is complete loss of function in 1 patient (4\%). Most patients who were independent walkers preoperatively resume independent walking within 2 weeks after undergoing the SDR technique. Patients who walked with assistance preoperatively take a slower postoperative course. Within 2 months, however, all patients show motor performance exceeding preoperative levels.

\section{Early complications:}

The major complications of SDR from our selected group include:

- Back pain: 22 patients (75\%).
- Wound infection: 3 patients (10\%).

- Paraplegia: 1 patient (3\%).

- Sensory loss: 1 patient (3\%).

- Hyperthesia: 1 patient (3\%).

- Bladder transient retention: 1 patient (3\%).

- CSF leak: 1 patient (3\%).

\section{Statistical analysis of data:}

The collected data were organized, tabulated and statistically analyzed using SPSS software statistical computer package version 22 (SPSS Inc, USA). For quantitative data, the mean, standard deviation (SD) were calculated. For qualitative data the number and percent distribution were calculated, Chi squared test was used as test of significance. For interpretation of results of tests of significance, significance was adopted at $\mathrm{P} \leq 0.05$. 


\section{RESULTS}

Table (1): Clinical Picture of patients

\begin{tabular}{|c|c|c|}
\hline & $\mathbf{N}$ & $\%$ \\
\hline Gait disturbance & 30 & $100.0 \%$ \\
\hline Spastic paraparesis & 30 & $100.0 \%$ \\
\hline Spastic quadriparesis & 15 & $50.0 \%$ \\
\hline \multicolumn{3}{|l|}{ Mentality state } \\
\hline Normal & 26 & $86.7 \%$ \\
\hline Decreased & 4 & $13.3 \%$ \\
\hline \multicolumn{3}{|l|}{ Speech } \\
\hline Normal & 11 & $36.7 \%$ \\
\hline Slurred & 17 & $56.7 \%$ \\
\hline Aphasia & 2 & $6.7 \%$ \\
\hline \multicolumn{3}{|l|}{ Sensation } \\
\hline Normal & 26 & $86.7 \%$ \\
\hline Cannot be assessed & 4 & $13.3 \%$ \\
\hline \multicolumn{3}{|l|}{ Sphincteric affection } \\
\hline Urine incontinence & 21 & $70.0 \%$ \\
\hline Global incontinence & 9 & $30.0 \%$ \\
\hline \multicolumn{3}{|l|}{ Cranial nerve affection } \\
\hline Normal & 18 & $60.0 \%$ \\
\hline Loss of hearing & 6 & $20.0 \%$ \\
\hline Unilateral 6th nerve palsy & 4 & $13.3 \%$ \\
\hline Bulbar dysphagia & 1 & $3.3 \%$ \\
\hline Loss of vision & 1 & $3.3 \%$ \\
\hline \multicolumn{3}{|l|}{ Aschworth's score } \\
\hline Score 1 & 4 & $13.3 \%$ \\
\hline Score 2 & 22 & $73.3 \%$ \\
\hline Score 3 & 4 & $13.3 \%$ \\
\hline
\end{tabular}

Outcome: Outcome of our operation is showing improvement of spasticity in 26 patients $(86.7 \%), 3$ patients stayed the same as pre-operative and 1 patient got worse than pre-operative.

According to our results, the most common complication is post-operative back pain (22 patients); $73.3 \%$ of our selected group, which is easily managed by analgesics, while other complications show very little percentage, wound infection (3 patients); $10 \%$ of our selected group, can be managed easily by antibiotics and regular wound care, other complications while low in percentage, still doesn't cause mortality (Table 2). 
Table (2): Outcome of trial and complications

\begin{tabular}{|c|c|c|c|}
\hline & & $\mathbf{N}$ & $\%$ \\
\hline \multirow{3}{*}{ Operative results } & Improved & 26 & $86.7 \%$ \\
\hline & Not improved & 3 & $10.0 \%$ \\
\hline & Got worse & 1 & $3.3 \%$ \\
\hline \multirow{7}{*}{ Complications } & Back pain & 22 & $73.3 \%$ \\
\hline & Wound infection & 3 & $10.0 \%$ \\
\hline & CSF leak & 1 & $3.3 \%$ \\
\hline & Hyperthesia & 1 & $3.3 \%$ \\
\hline & Hypothesia & 1 & $3.3 \%$ \\
\hline & Paraplegia & 1 & $3.3 \%$ \\
\hline & Transient urine retention & 1 & $3.3 \%$ \\
\hline
\end{tabular}

Our results is showing improved outcome of cases showing normal mental state pre operatively than patients with decreased mental state.
Our results is showing improved outcome of cases showing higher Aschworth's score pre operatively (Table 3).

Table (3): Relation between Mental status, pre-operative Aschworth's score and outcome

\begin{tabular}{|c|c|c|c|c|c|c|c|c|}
\hline & \multicolumn{2}{|c|}{ Improved } & \multicolumn{2}{|c|}{ Not improved } & \multicolumn{2}{|c|}{ Got worse } & \multirow{2}{*}{ P-value ${ }^{\#}$} \\
\hline & & $\mathbf{N}$ & $\%$ & $\mathbf{N}$ & $\%$ & $\mathbf{N}$ & $\%$ & \\
\hline \multirow{2}{*}{$\begin{array}{l}\text { Mentality } \\
\text { state }\end{array}$} & Normal & 26 & $100.0 \%$ & 0 & $0.0 \%$ & 0 & $0.0 \%$ & \multirow{2}{*}{$<0.0001^{*}$} \\
\hline & Decreased & 0 & $0.0 \%$ & 3 & $75.0 \%$ & 1 & $25.0 \%$ & \\
\hline \multirow{3}{*}{$\begin{array}{l}\text { Aschworth's } \\
\text { score }\end{array}$} & Score 1 & 4 & $100.0 \%$ & 0 & $0.0 \%$ & 0 & $0.0 \%$ & \multirow{3}{*}{$<0.0001^{*}$} \\
\hline & Score 2 & 22 & $100.0 \%$ & 0 & $0.0 \%$ & 0 & $0.0 \%$ & \\
\hline & Score 3 & 4 & $0.0 \%$ & 3 & $75.0 \%$ & 1 & $25.0 \%$ & \\
\hline
\end{tabular}

*Patient's with good pre-operative mental state has a better prognosis, with significant P- value $<0.0001$.

*Patient's with higher pre-operative modified Aschworth's score has a better prognosis, with significant Pvalue $<0.0001$

\section{Case Presentation}

A boy, 5 years old, from Mansoura, was complaining of inability to walk properly, he was known to suffer from cerebral palsy since birth, due to obstructed labour. He has delayed motor milestones, while mental milestones are normal. He also has urine incontinence.

By examination, he has spastic both lower limbs, motor power in both lower limbs is 3 with hyperreflexia, while intact both upper limbs with normal tone and reflexes, sensation is intact in four limbs, modified Aschworth's score is 2, he can't walk, but can stand with support and can crawl. Otherwise, normal mentality, speech, intelligence and memory. Also, no spinal, cranial nor orthopedic deformities. MRI brain and whole spine were done, X-ray of LSS and hip joint, all were normal.

He had medical treatment in form of baclofen $10 \mathrm{mg}$ tabs which had mild relief of spasticity; also, he had physiotherapy sessions and Botox injection which couldn't give the patient's parents a satisfying result.

\section{Surgical technique:}

- The patient is positioned prone with EMG needle electrodes placed into five muscle groups of each leg 
(bilaterally in the adductor longus, vastus lateralis, anterior tibialis, medial hamstring, and medial gastrocnemius muscles) and the external anal sphincter muscles (Figures 1, 2, 3).

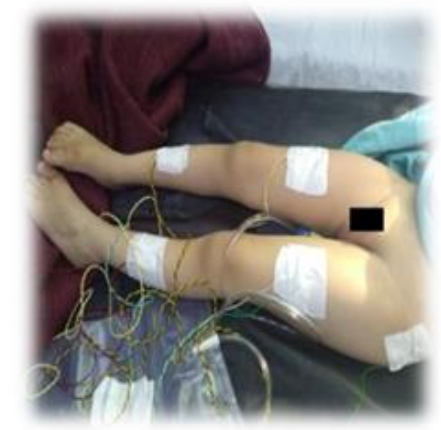

Figure (1)

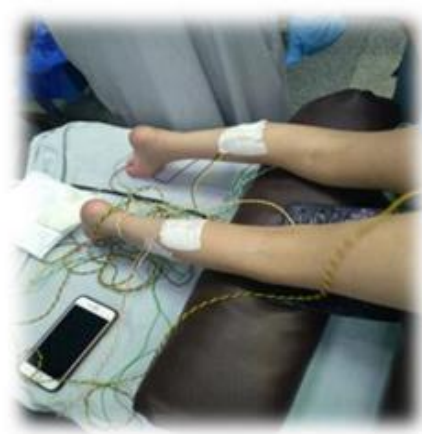

Figure (2)

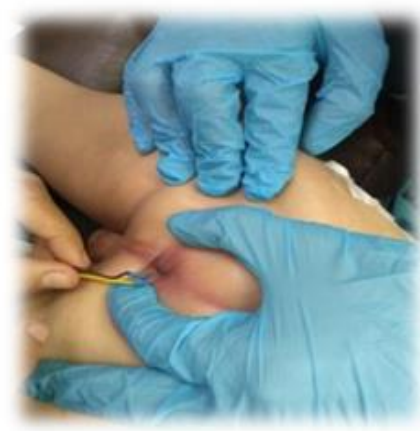

Figure (3)
- Skin incision is done exposing from L1 to S1, followed by muscle separation taking in consideration avoidance of excessive bleeding and very meticulous hemostasis (Figure 4).

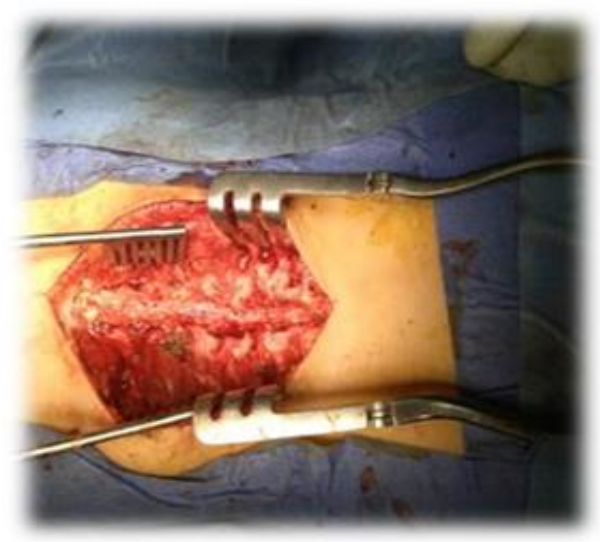

Figure (4)

- An L2 to S1 laminoplasty was containing the whole cauda equina performed to expose the entire dura (Figure 5).

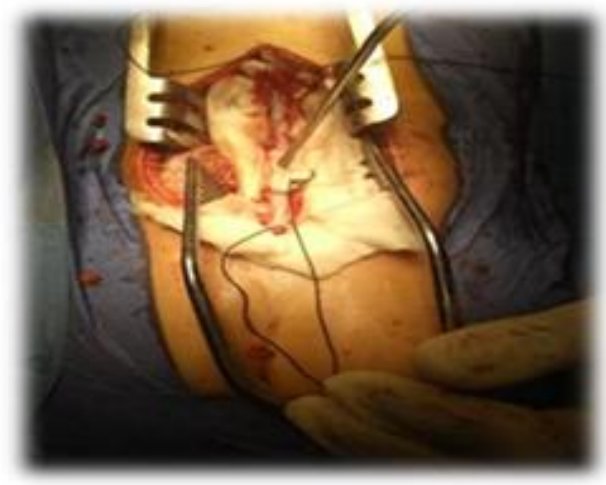

Figure (5) 
- A dural incision is made (Figure 6).

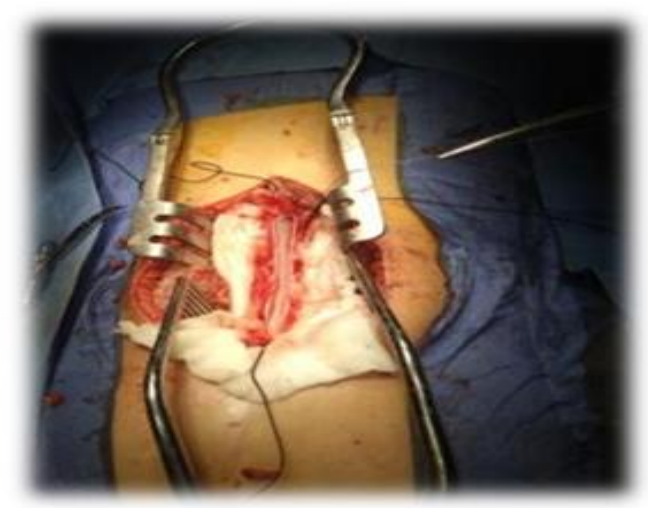

Figure (6)

- At this point, EMG activities are continuously monitored to determine if any movement of the nerve roots evokes EMG activities. Stretching and pressure on the ventral roots but not on the dorsal roots evoke EMG activities and often movement of the patient's lower extremity (Figure 7).

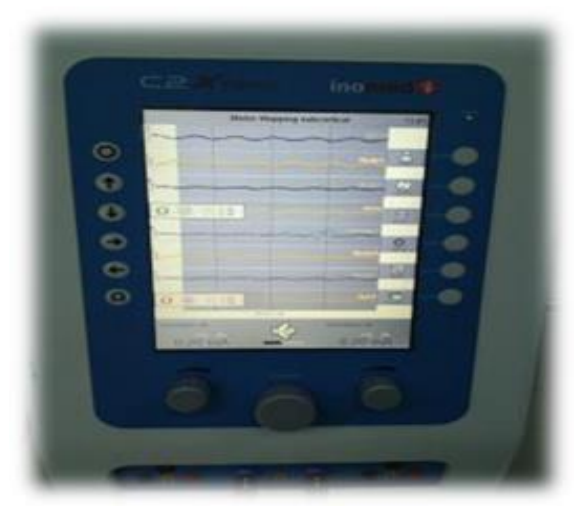

Figure (7)

- Next, the L2 spinal roots are identified at the neural foramen (Figure 8).

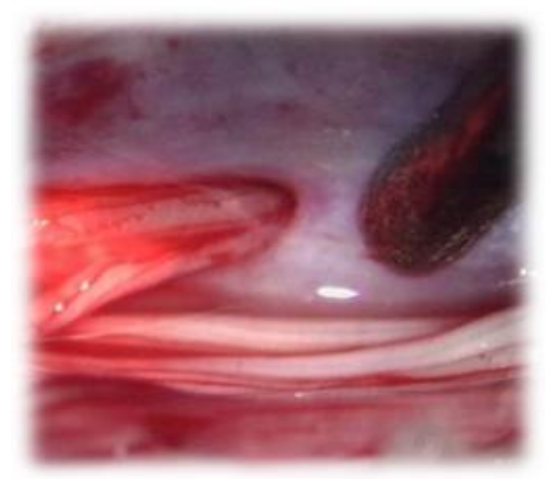

Figure (8) 
- After the innervation of a dorsal root is determined, the root is sharply

subdivided into three to five smaller rootlets of equal size (Figure 9).

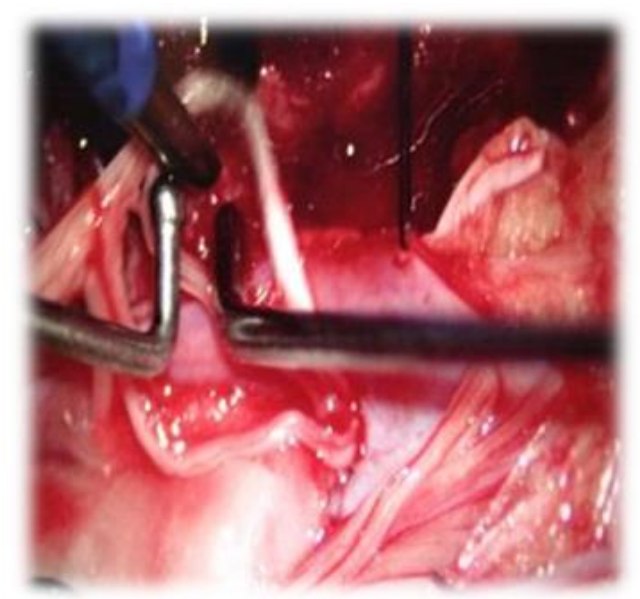

Figure (9)

- The rootlet fascicles are suspended over two hooks of the rhizotomy probes, then, application of stimulation with $50 \mathrm{~Hz}$ frequency and
$3 \mathrm{~mA}$ to each rootlet, The reflex response is then graded according to the following criteria: (Figures 10, 11).

\begin{tabular}{|c|c|}
\hline Grade & Electromyographic Response \\
\hline 0 & Unsustained or single discharge to a train of stimuli \\
\hline $1+$ & $\begin{array}{l}\text { Sustained discharges from muscles innervated } \\
\text { through the segment stimulated in the ipsilateral } \\
\text { lower extremity }\end{array}$ \\
\hline $2+$ & $\begin{array}{l}\text { Sustained discharges from muscles innervated } \\
\text { through the segment stimulated and immediately } \\
\text { adjacent segments }\end{array}$ \\
\hline $3+$ & $\begin{array}{l}\text { Sustained discharges from segmentally innervated } \\
\text { muscles and muscles innervated through segments } \\
\text { distant to the segment stimulated }\end{array}$ \\
\hline $4+$ & $\begin{array}{l}\text { Sustained discharges from contralateral muscles } \\
\text { with or without sustained discharges from the } \\
\text { ipsilateral muscles }\end{array}$ \\
\hline
\end{tabular}

Figure (10) 


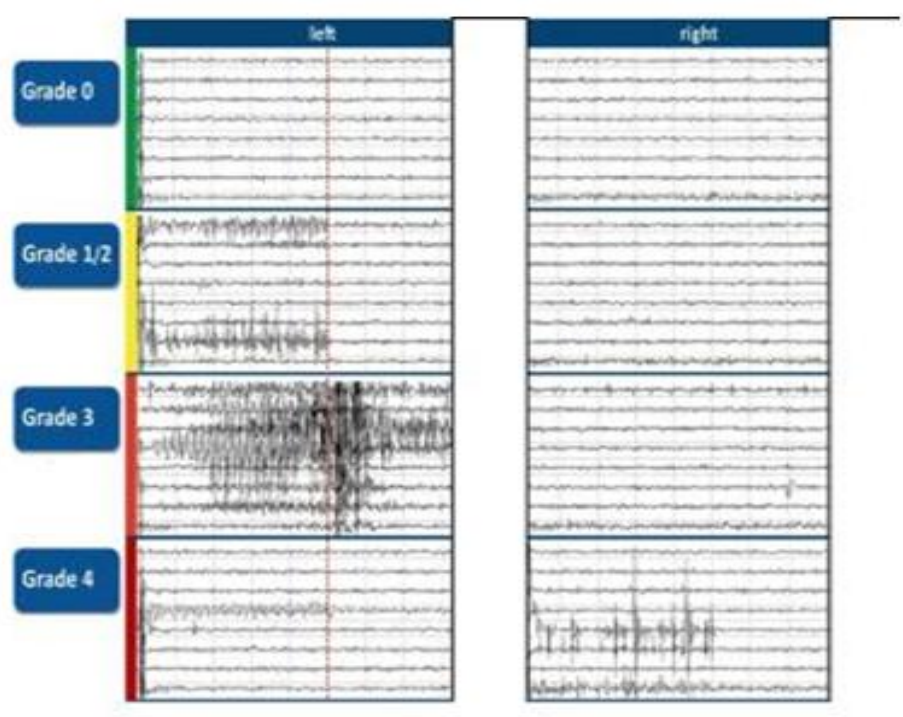

Figure (11)

- The rootlets producing +3 and +4 responses were cut, and those producing +1 and +2 responses were sometimes spared. At least one rootlet was left irrespective of EMG responses to avoid postoperative sensory loss. The procedure was performed in sequence on the remaining L3-S2 dorsal roots bilaterally (Figure 12).

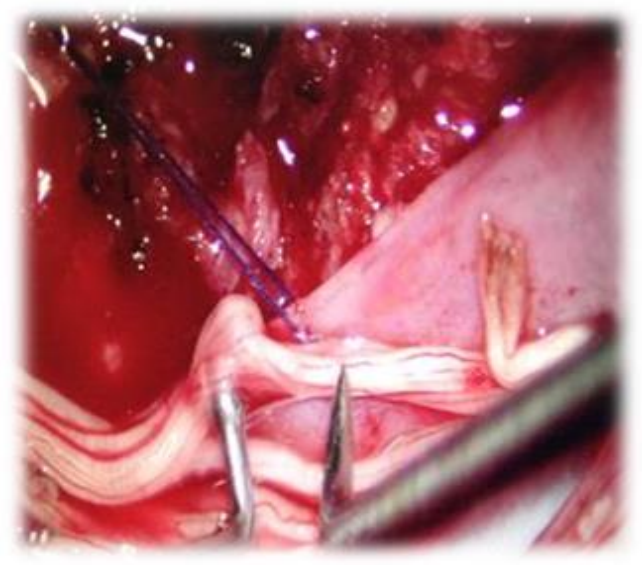

Figure (12)

- At this case, the percentage of the cut rootlets to the corresponding roots was as following (Table 4)

\begin{tabular}{|c|c|c|c|c|c|c|}
\hline & L2 root & L3 root & L4 root & L5 root & S1 root & S2 root \\
\hline $\mathrm{Rt}$ & $50 \%$ & $40 \%$ & Spared & $30 \%$ & $60 \%$ & $30 \%$ \\
\hline $\mathrm{Lt}$ & $60 \%$ & $50 \%$ & Spared & $40 \%$ & $30 \%$ & $30 \%$ \\
\hline
\end{tabular}

- Note that we spared L4 roots as they are main nerve supply to muscles facilitating knee extension and maintaining the ability of patient to stand up properly depending on the tone of knee extensors group.

- Finally, the intradural space is irrigated with saline solution. Bipolar 
cautery is required for control of bleeding from the cut ends of rootlets. The dura is closed in a water tight

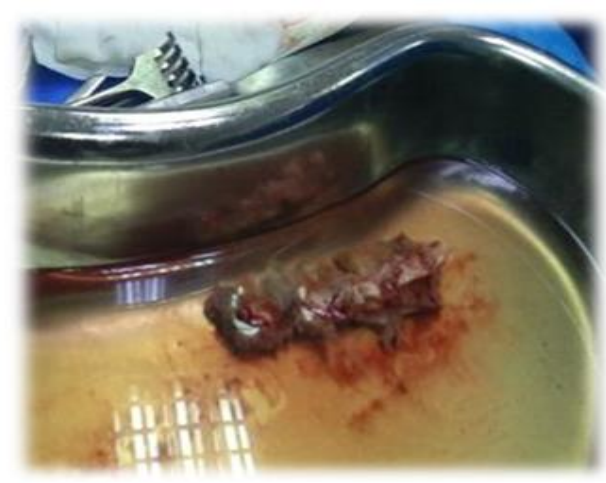

Figure (13)

\section{Postoperative Care:}

Patient stayed overnight in the intensive care unit where he received an intravenous proper analgesia with wide coverage of antibiotics.

Patient was transferred to the ward the next day, then, was allowed to sit, and physical therapy was started. The patients were discharged to home after stabilization and receive outpatient physical therapy from local therapists.

\section{DISCUSSION}

Dorsal rhizotomy was first performed primarily for the purpose of spasticity relief by Foerster in 1913. He relieved lower extremity spasticity via total rhizotomy of the posterior roots of L2, L3, L5, S1, and S2, sparing L4. Unfortunately, the procedures were discontinued because of the unacceptable level of sensory complications such as sensory ataxia, anesthesia, and congestive ulceration of the leg (Foerster, 1919).

To identify an abnormal posterior root and to limit sensory complications, Fasano and his colleagues in 1978 modified Foerster's method. In their "functional manner, the removed bones to be put back, then proper layered closure of incision was done (Figures 13, 14).

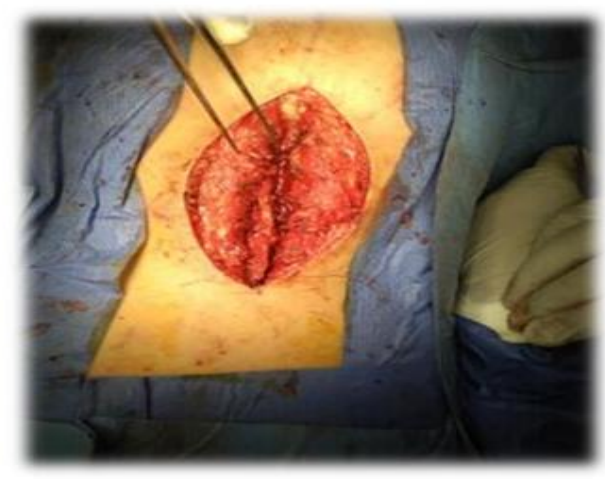

Figure (14)

\section{Postoperative Course:}

Motor power in both lower limbs is the same within the hospital, while there was dramatic decrease in muscle tone and spasticity. Also, sensation was intact. However, urinary incontinence wasn't assessed as the patient was on urinary catheter.

No major post-operative complications were detected, except moderate low back pain which was managed with analgesics.

posterior rhizotomy," they tested an individual posterior rootlet by using intraoperative electrical stimulation before resection, to determine the contribution of the afferent rootlet to muscle tone. This technique made it possible to achieve significant relief of spasticity without profound sensory complications (Grunt et al., 2014).

In our study, we were able to achieve significant results using Fasano's technique, depending on intra operative EMG monitoring with sparing of sensory rootlets decreasing the possibility complications as sensory loss, and preventing injury to ventral motor roots preventing post-operative weakness. 
Another question that needs to be addressed concerns the amount and choice of posterior rootlets to be cut to achieve optimal relief of spasticity and improvement of motor function without adverse effects. There is significant variation between authors with respect to both of these criteria. Many workers agree that more than $50 \%$ of each rootlet tested would have to be cut for the adequate relief of spasticity, regardless of the severity of its abnormality on EMG monitoring (Grunt et al., 2014).

In our study, we achieved significant results in our patients with sectioning 30$60 \%$ of rootlets, with preservation of motor power and no sensory loss.

According to our results, an important factor that may improve outcome and prognosis of patients is the pre-operative mental state, as patients with acceptable mental ability has the potential to participate in more active physiotherapy programs that improve outcome greatly.

However, even with decreased mentality there is post-operative decrease in muscle tone and reflexes, which may aid in making patient's decubitus less prone to pressure sores, and make the patient easier to handle, so, the proper care can be achieved.

Also according to our study, the higher the grade of Aschworth's score is a good prognostic factor of achieving faster improvement of spasticity and gait.

SDR is not a cure for cerebral palsy. The procedure offers spastic CP children improved motor capabilities and increased levels of functioning. Achieving maximal benefits depends on how much and which of the posterior rootlets are cut.
The very few fatal complications and little percentage of them according to our results, make SDR surgery a good solution to relieve the spastic Para paresis and improve gait with little risk.

\section{CONCLUSION}

SDR is a surgical procedure that can decrease spasticity of both lower limbs of patients with cerebral palsy, and can improve motor power of affected lower limbs with physiotherapy programs and rehabilitation, giving the patient's the ability to improve gait and balance while walking either with or without assistance, especially when patients have high mentality and low spasticity grading according to modified Aschworth's score, with very little risk of complications.

This surgery can be performed efficiently in most of hospitals' surgical rooms settings with no need for special materials or equipment, except for EMG monitor which can be brought easily to OR setting with low cost, which is acceptable according to the good results that the surgery can benefit the patients with.

\section{REFERENCES}

1. Foerster $O$ (1919): On the indications and results of the excision of posterior spinal nerve roots in men. Surg Gynecol Obstet., 16: 463: 73 .

\section{Graham D, Aquilina K, Mankad} $K$ and Wimalasundera N. (2018): Selective dorsal rhizotomy: current state of practice and the role of imaging. Quant Imaging Med Surg., 8:209-218. 
3. Grunt S, Fieggen AG, Vermeulen RJ, Becher JG and Langerak NG. (2014): Selection criteria for selective dorsal rhizotomy in children with spastic cerebral palsy: a systematic review of the literature. Dev Med Child Neurol., 56:302-312.

4. Lieber RL, Roberts TJ, Blemker SS, Lee SSM and Herzog W. (2017): Skeletal muscle mechanics, energetics and plasticity. J Neuroeng Rehabil., 14:108.
5. Lynn AK, Turner $M$ and Chambers HG. (2010): Surgical management of spasticity in persons with cerebral palsy. PMR., 1:834-838.

6. Nahm NJ, Graham HK, Gormley ME and Georgiadis AG. (2018): Management of hypertonia in cerebral palsy. Curr Opin Pediatr., 30:57-64. 


\section{التذخل الجر احي لعلاج تخشب الطرفين السفليين في حالات

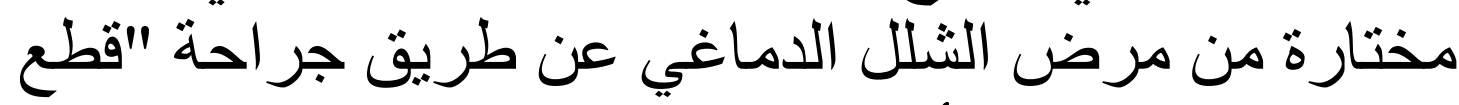

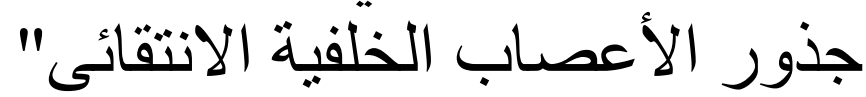

أحمد ناصر عبد الحميد السيد، مأمون أبو شوشة، محمد أحمد اللباد، علاء رشاد إبراهيم قسم جراحة المخ والأعصاب، كلية الطب، جامعة الأزهر

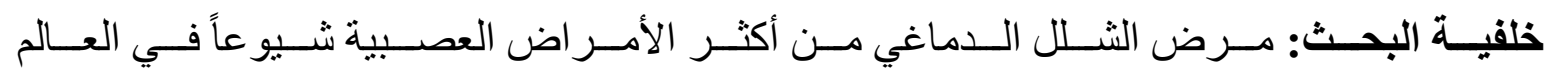

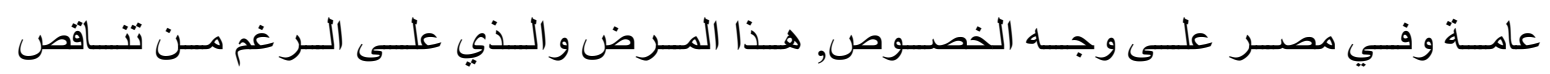

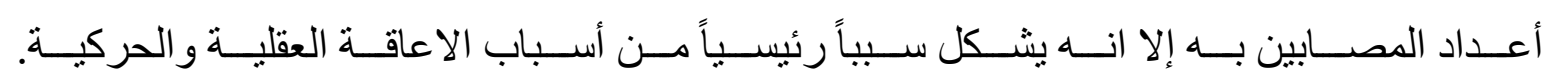

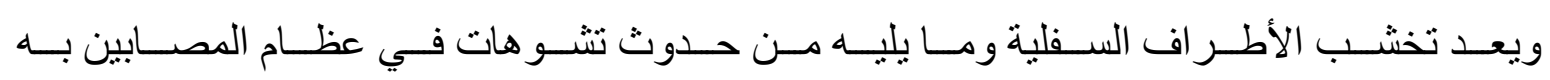

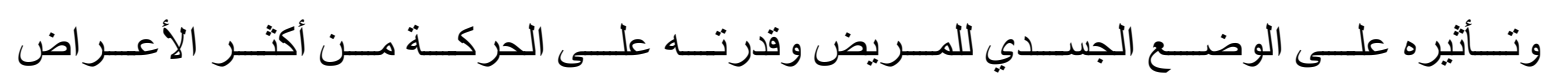

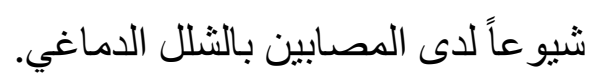

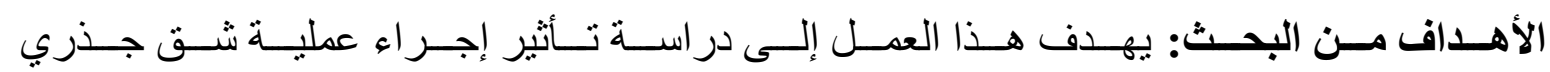

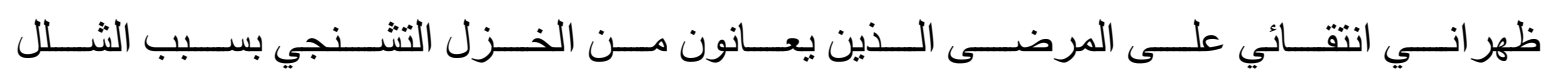

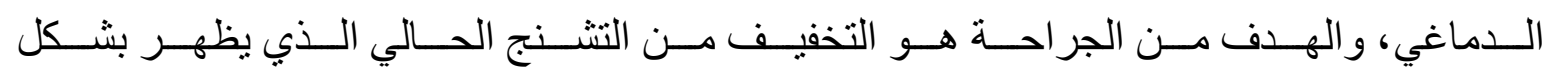
أساسي في الأطراف السفلية، وتحسين وظيفة المحرك.

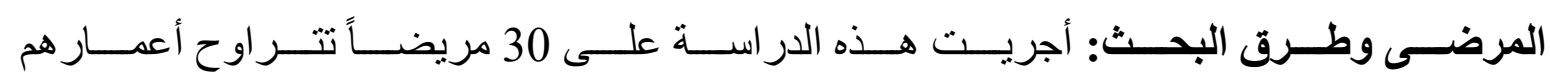

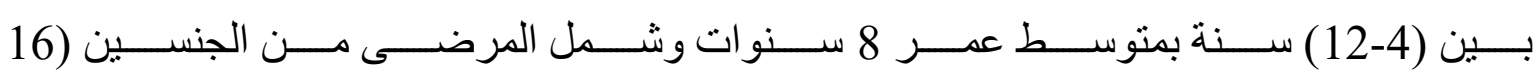

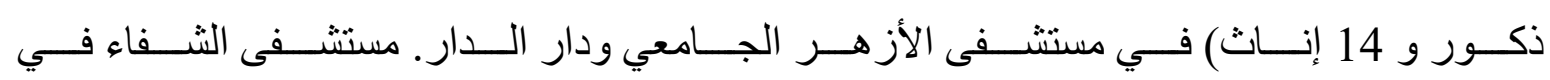
الفترة من يناير 2019 إلى أغسطس في الت 2020.

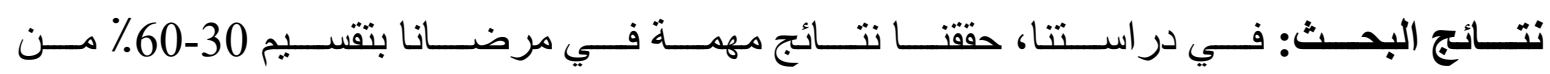

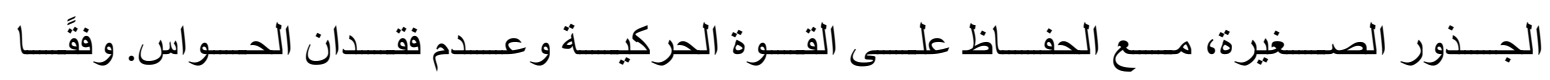

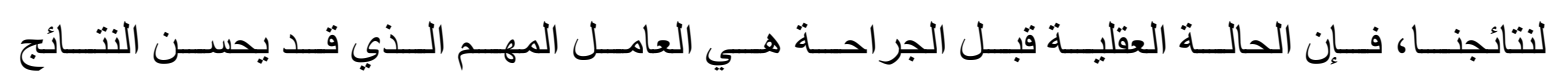

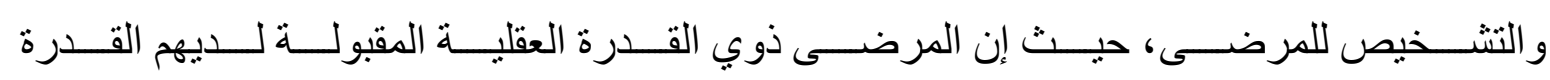

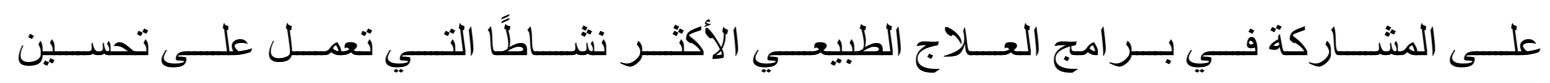

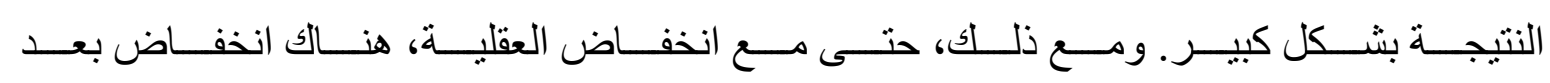

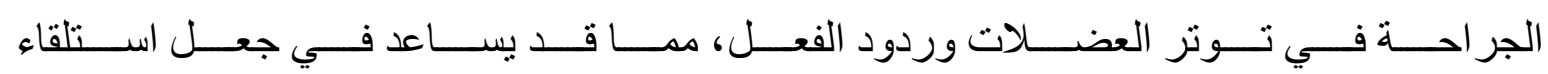




\section{SURGICAL MANAGEMENT OF SPASTIC DIPARESIS IN SELECTED...}

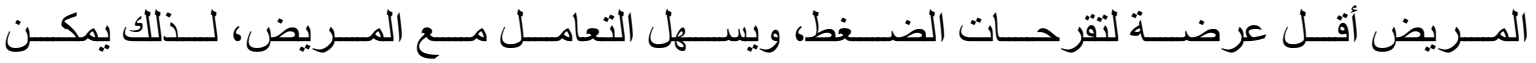

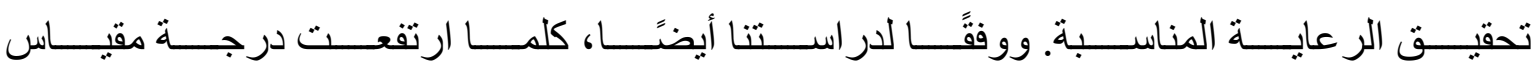
"آشورث" يعد عاملاً تنبؤيًا جيدًا لتحقيق تحسن أسرع في التشنج و المشي.

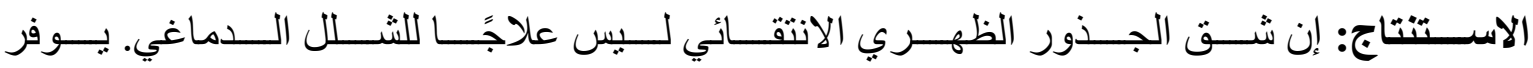

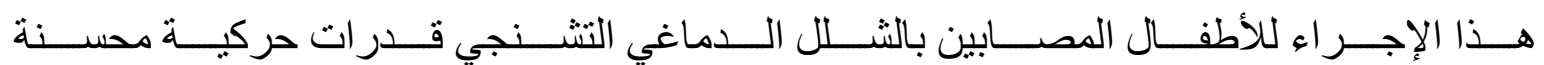

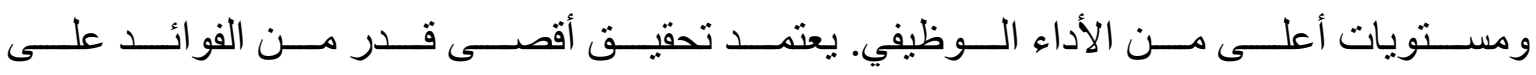
مقدار وأي من الجذور الخلفية يتم قطعها.

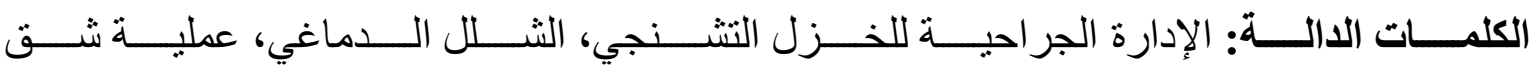
الجذور الظهرية الانتقائية. 